\title{
Paul RASSE, La rencontre des mondes : diversité
} culturelle et communication

Paris, A. Colin, coll. Sociétales, 2006, 301 p.

Jean Zoungrana

\section{CpenEdition}

Journals

Édition électronique

URL : http://journals.openedition.org/questionsdecommunication/2564

DOI : 10.4000/questionsdecommunication.2564

ISSN : 2259-8901

Éditeur

Presses universitaires de Lorraine

Édition imprimée

Date de publication : 31 décembre 2007

Pagination : 439-441

ISBN : 978-2-86480-849-7

ISSN : 1633-5961

Référence électronique

Jean Zoungrana, «Paul RASSE, La rencontre des mondes : diversité culturelle et communication », Questions de communication [En ligne], 12 | 2007, mis en ligne le 12 avril 2012, consulté le 08 avril 2021. URL : http://journals.openedition.org/questionsdecommunication/2564 ; DOI : https://doi.org/ 10.4000/questionsdecommunication.2564

Ce document a été généré automatiquement le 8 avril 2021.

Tous droits réservés 


\section{Paul RASSE, La rencontre des mondes : diversité culturelle et communication}

Paris, A. Colin, coll. Sociétales, 2006, 301 p.

Jean Zoungrana

\section{RÉFÉRENCE}

Paul RASSE, La rencontre des mondes : diversité culturelle et communication. Paris, A. Colin, coll. Sociétales, 2006, $301 \mathrm{p}$.

1 Voici un ouvrage très didactique qui prend le parti de s'interroger sur la manière dont s'opère la rencontre entre des mondes différents, prolongeant ainsi des recherches antérieures sur la question de la diversité des cultures populaires confrontées à la globalisation (Paul Rasse, Nancy Midol, Fathi Triki, dirs, Unité et diversité, Les identités culturelles dans le jeu de la mondialisation, Paris, Éd. L'Harmattan, 2002). En effet, à la différence de l'approche classique américaine de l'anthropologie de la communication qui place ses études sur un plan microsocial, la tradition francophone s'intéresse davantage au niveau macrosocial qui postule que la connaissance des civilisations antérieures est indispensable à la compréhension des sociétés contemporaines. Mais autant l'anthropologie passe pour une approche globale de l'homme, autant cette approche n'est productive qu'en isolant des secteurs particuliers. C'est ce qu'avait compris et entrepris Claude Lévi-Strauss à propos des mythes; c'est ce que propose ici Paul Rasse avec la communication, en faisant un aller-retour entre macro et microsocial. Des réseaux matériels de transport aux réseaux virtuels, hertziens, électroniques de circulation de l'information, la communication, dans son sens le plus général, est bien ce qui semble indispensable au vivre ensemble de toute communauté humaine. Et à ce titre, les sic (sciences de l'information et de la communication) ont un rôle essentiel à jouer: elles permettent de souligner l'importance historique des processus de communication et de proposer une vision globale des phénomènes de 
communication en prenant appui sur l'anthropologie comme discipline constituée de longue date et comme science de l'altérité.

2 Quelles sont donc les grandes lignes d'une telle anthropologie de la communication? En se focalisant sur l'aire géographique de l'Europe et de la Méditerranée, l'auteur structure son ouvrage en deux parties. La première s'intéresse à l'histoire des processus de communication qui traversent les sociétés et les civilisations, la seconde s'interroge sur les mutations induites parles NTIC (nouvelles technologies de l'information et de la communication) dans les sociétés contemporaines et, plus précisément, sur les processus d'uniformisation du monde et d'atomisation de la diversité culturelle.

3 Ainsi, dans les dynamiques de la communication, Paul Rasse se sert-il de l'anthropologie historique pour parcourir l'histoire de l'humanité. Il situe son départ dans l'émergence des premières formes de sociabilité qui sont aussi les premiers systèmes d'échange et de communication chez les chasseurs-cueilleurs nomades pour aboutir à la révolution de l'informatique et de la connectique qui ouvre des perspectives immenses et encore insoupçonnées. Ce parcours documenté et condensé lui permet de souligner l'importance de la communication tant celle-ci structure l'histoire des hommes. En effet, si l'échange permet de tisser des liens entre les premières communautés, les contraintes environnementales favorisent la diversité des cultures comme les réseaux cinétiques de communication ont contribué à l'émergence des grandes civilisations. La révolution des moyens de communication conduit plus que jamais au brassage des sociétés entre elles ainsi qu'à un processus d'accumulation des savoirs et de confrontation des connaissances. Aussi Paul Rasse peut-il affirmer que : « la connectique et l'informatique donnent à la circulation des savoirs une dimension planétaire » (p. 176).

4 Qu'en est-il alors des perspectives anthropologiques dans le monde contemporain ? À ce propos, l'auteur s'emploie à défendre la diversité des cultures en prenant appui sur les réseaux télématiques. En effet, la diversité est de toujours. Or, aujourd'hui, la technologie unidimensionnelle œuvre globalement à l'uniformisation des modes de vie. C'est le cas de la cuisine mais aussi de l'alimentation dont on sait l'importance pour la diversité des cultures. Désormais, c'est à l'échelle planétaire qu'il faut penser les pratiques alimentaires avec l'application de normes de plus en plus rigoureuses. L'organisation de la famille est elle aussi bouleversée. À la vérité, la diversité des formes familiales qui existait à l'échelle de l'humanité se trouve de nos jours ramenée à un modèle dominant, la famille nucléaire qui, en crise, se voit réduite à son tour à un seul adulte monoparental. Enfin, avec la sociabilité postmoderne des réseaux, on est inscrit dans l'ère de l'éphémère et des communautés virtuelles dont il faut en être ; sinon, on est d'emblée frappé d'exclusion et solitude.

Deux perspectives sont alors proposées pour la défense de la diversité des cultures. L'une, horizontale et planétaire, utilise les TIC pour structurer et fédérer les formes alternatives à la globalisation hégémonique et univoque. L'autre, verticale et historique, s'inscrit dans les territoires afin de faire du terroir un sanctuaire indispensable au renouvellement de la diversité des cultures menacée d'appauvrissement Et dans ce processus de patrimonialisation et de développement local, les NTIC, avec leur dynamique propre, semblent indispensables à travers les possibilités qu'elles offrent: création de site, réservation en ligne, mise en lien des différents acteurs, etc. C'est donc avec raison que des organismes internationaux tel 
l'Unesco, insistant sur la nécessité de réduire la fracture numérique entre le Nord et le Sud, misent sur la connectique et les TIC.

6 Tout porte à penser que la sauvegarde de la diversité des cultures passe par l'invention de nouvelles formes de sociabilité et de résistance. Face à la globalisation qui conduit immanquablement à l'émergence d'une seule culture, le mouvement altermondialiste, par exemple, se veut une alternative pertinente. Dans la dénonciation des sommets réunissant les décideurs de la planète - Seattle en 1999, Gènes en 2001, Cancùn en 2003 ou dans l'organisation des forums sociaux mondiaux -Porto Alegre en 2003, Bombay en 2004 -, la place des NTIC dans cette construction de formes de sociabilité postmoderne et respectueuse de la diversité des cultures semble manifeste. Et dans cette tentative de création d'un espace public planétaire, se joue sans doute l'avenir de la planète.

7 Au regard des profondes mutations imposées par les NTIC à toute l'humanité, ce livre devrait s'intituler Eloge de la communication tant celle-ci est omniprésente en ses formes variées; et tout comme le sous-titre, qui en porte témoignage, reste parfaitement explicite quant à son objet.

De la sorte, à la lecture, on mesure comment et combien la communication - toujours et encore celle-ci - est au cœur de toute société humaine. Didactique encore, La rencontre des mondes est organisé, en chaque tête de chapitre, autour d'une série de questions ou de tracés problématiques auxquelles l'auteur s'efforce de répondre avec un esprit de synthèse contenu; ce qui en facilite la lecture mais aussi ce qui fait de ce texte un quasi manuel de l'usage de l'anthropologie en communication. Finalement, il souffle dans ce croisement de l'anthropologie et des sic un vent nouveau de critique de la mondialisation et de la pensée unique libérale, qui donne à réfléchir aux grands enjeux de notre époque.

\section{AUTEURS}

\section{JEAN ZOUNGRANA}

CRESS, université Strasbourg 2

Jean.Zoungrana@umb.u-strabg.fr 